\title{
Monitoring the Sonographic Ovarian Dynamics and Pregnancy Rate in Cyclic Murrah Buffalo Cows Synchronized with Prostaglandin F2 $\alpha$
}

\author{
Mohammad Harun-or-Rashid ${ }^{1,2, *}$, SK Phulia ${ }^{3}$, Mir Md. Iqbal Hasan ${ }^{1,4}$, Mohammad Musharraf \\ Uddin Bhuiyan $^{1}$, Nasrin Sultana Juyena ${ }^{1}$ and Rakesh Kumar Sharma ${ }^{3}$ \\ ${ }^{1}$ Department of Surgery and Obstetrics, Bangladesh Agricultural University, Mymensingh-2202, Bangladesh \\ ${ }^{2}$ Department of Livestock Services, Krishi Khamar Sarak, Farmgate, Dhaka-1215, Bangladesh \\ ${ }^{3}$ Division of Animal Physiology and Reproduction, Central Institute for Research on Buffalo (CIRB), Hisar, Haryana \\ 125001, India \\ ${ }^{4}$ Department of Physiology, Sylhet Agricultural University, Sylhet-3100, Bangladesh
}

Received October 20, 2019

Revised November 29, 2019

Accepted March 10, 2020

\section{*Correspondence}

Mohammad Harun-or-Rashid

E-mail: harunphd2016@gmail.com

ORCID

https://orcid.org/0000-0003-2973-3585
ABSTRACT The objective of this research work was to know ovarian dynamics and pregnancy rate of cyclic Murrah buffalo cows with induced estrus by administration of prostaglandin F2 $\alpha$ (PGF2 $\alpha$ ) and timed artificial insemination (TAI) with frozen thawed semen. A total of 31 female buffaloes were selected for the study. The buffalos having matured CL observed by ultrasonography were given one intra muscular injection of cloprostenol $500 \mu \mathrm{g}$ and TAl was performed using frozen thawed semen of Indian Murrah buffalo bull. Results showed that 90.32\% (significantly, at $p<0.05$ ) cows explore the sign of heat after injection of PG and $67.85 \%$ (significantly, at $p<0.05$ ) cows were become pregnant out of 28 inseminated (TAI) cows. In the 28 inseminated (TAI) cows, average number of smaller and larger size of follicles were non-significantly $(p>0.05)$ higher at day 3 post PG injection, but the medium size of follicles was nonsignificantly $(p>0.05)$ higher at PG injection. At day 3 post PG injection the diameter of follicles was significantly $(p<0.05)$ higher, but the diameter of $C L$ was significantly ( $p$ $<0.01$ ) lower compared at PG injection. At PG injection the diameter of largest follicle was non-significantly differences $(p>0.05)$ in between pregnant and non-pregnant cows. But at day 3 post PG injection it was significantly $(p<0.01)$ higher in pregnant cows compared to non-pregnant cows. The number of small, medium, and large follicles at PG injection and at day 3 post PG injection were non-significantly $(p>0.05)$ difference in between pregnant and non-pregnant buffalo cows. Finally, it is concluded that the $\mathrm{CL}$ was effectively regresses and induced the sign of heat in buffalo cows and after Al the cows were become pregnant with significant rate. The study will help to the veterinarian and researcher to know the efficacy of PG injection and Al for reproductive efficiency in buffalo cows.

Keywords: Al (artificial insemination), CL (corpus luteum), follicular diameter, PGF2 $\alpha$ (prostaglandin $\mathrm{F} 2 \alpha$ ) 


\section{INTRODUCTION}

Buffaloes play an important role in livestock by producing meat and milk with containing low cholesterol and high amount of fat. However, their productivity is inadequate with inherent problems of poor estrus expression specially in low breeding season and prolonged intercalving interval which are the main obstacle of the reproductive efficiency of female buffaloes (Drost et al., 1985; Madan, 1988; Prakash, 2002). The buffalo farmers are facing this reproductive problem mainly in summer season when environmental temperature is high and fertility decreases intensely. In this period pregnancy rate also decreases because difficult to detect estrus and farmers do not perform natural or artificial insemination (AI) services to their buffalo cows in proper time. To overcome these sorts of problem and to improve reproductive efficiency, different estrus and ovulation synchronization protocol have to be practice. In buffalo like cattle approaches for estrus synchronization have utilized prostaglandin F2 $\alpha$ (PGF2 $\alpha$ ) alone or in combination with GnRH (De Renis and Lopez-Gatius, 2007). These pharmaceutical agents regress the corpus luteum (CL), regulate growth/regress of follicle and ovulation following luteolysis with prostaglandin. The luteolytic effect of PGF2 $\alpha$ in cattle was described by several workers in the early 1970s. In dairy cattle, several studies confirmed the capability of PGF $2 \alpha$ and its synthetic analogues like alfaprostol (Randel, 1988), clorprostenol (Cooper and Rowson, 1975), fenprostalene (Stotts et al., 1987) and luprostiol (Plata et al., 1990) to initiate the regression of mature CL in the ovary, thus provoking and synchronizing estrus of animals. Though the estrus synchronization appeared in the world since 45 years (Baruselli et al., 2013) but there is still considerable limitation. In cattle normally 2-4 follicular wave are present during estrus cycle where only $20-30 \%$ primordial follicles present compared as cattle and 2-3 follicular wave and mostly 2 follicular waves are very common in buffalo (Settergren, 1987; Ty et al., 1994; Baruselli et al., 2013). For that reason the results of estrus synchronization in buffaloes are expected to be low (Campanile et al., 2010).

In recent year ultrasound using as a powerful technique for examination of reproductive organ in large animals and mainly used for knowing cyclic status of animal, differentiating between estrus and silent estrus, ovarian pathological conditions like various types of ovarian cyst
(Farin et al., 1990) and tumours (Kahn and Ludlow, 1989), early pregnancy diagnosis, fetal age and sex determination, fetal viability and assessing the uterus including its content. To study of follicular dynamics in large animal and development of several protocols to control ovarian function for timed artificial insemination (TAI) ultrasound has a vital role for improving reproduction of animals (Adams et al., 2008). The current study has revealed that ultrasonography is a key useful tool in buffaloes to study luteal and follicular diameter in different days. In assessing the status of ovarian structures e. g, follicle and CL in cyclic and non-cyclic buffaloes, ultrasonography has proved to be a valuable tool which helped the detecting of estrus of the animals. For this purpose, transrectal ultrasonography was carried out in the buffaloes at a definite interval to assess the follicular and luteal status and pregnancy condition of the animal.

\section{MATERIALS AND METHODS}

\section{Study area and duration}

The study was implemented in ICAR-Central Institute for Research on Buffaloes, Hisar, Haryana, India. The study was conducted from 19 December, 2018 to 30 March, 2019.

\section{Selection of animals and data collection}

The desired buffalo cows which were in normal estrus cycle considered for the study. A total 31 female buffalo cows were selected for the experiment to observe the $\mathrm{CL}$ and follicular diameter in both ovaries by the ultrasound examination. Good uterine tone and good vaginal discharge (GTGD) of the selected animals were also observed.

\section{Ultrasound machines and transducers}

The ultrasonography was applied for the examination of follicles and CL in both ovaries of selected animals by the digital ultrasound machine (Model: 320A Justvision TOSHIBA), equipped with $\mathrm{B}$ mode PVF738F microconvex intraoperative $7 \mathrm{MHZ}$ probe for characteristics of follicles and CL.

\section{Ultrasonographic examination}

At first animals were restrained properly without use of any tranquilizing agents and then faecal material was 
removed from the rectum and ovaries were located. The transducer was moved along the dorsal surface of the reproductive tract and then it was moved laterally to examine the ovaries. Ovaries were scanned by visualizing the structures in each ovary by sliding the transducer from medial to the lateral aspect of the ovary. Total numbers of small, medium and large size ovarian follicles at the time of PG injection and after 3 days of PG injection were recorded. Diameters of follicles divided in to three groups such as $<3 \mathrm{~mm}$ (small), $\geq 3-<10 \mathrm{~mm}$ (medium) and $\geq 10$ $\mathrm{mm}$ (large) data were recorded at the time of PG injection and after 3 days of PG injection. Diameter of CL in cyclic buffaloes and pregnancy rate of buffaloes were recorded. The measured largest follicle and diameter of CL symbolically presented in Fig. 1 and Fig. 2.
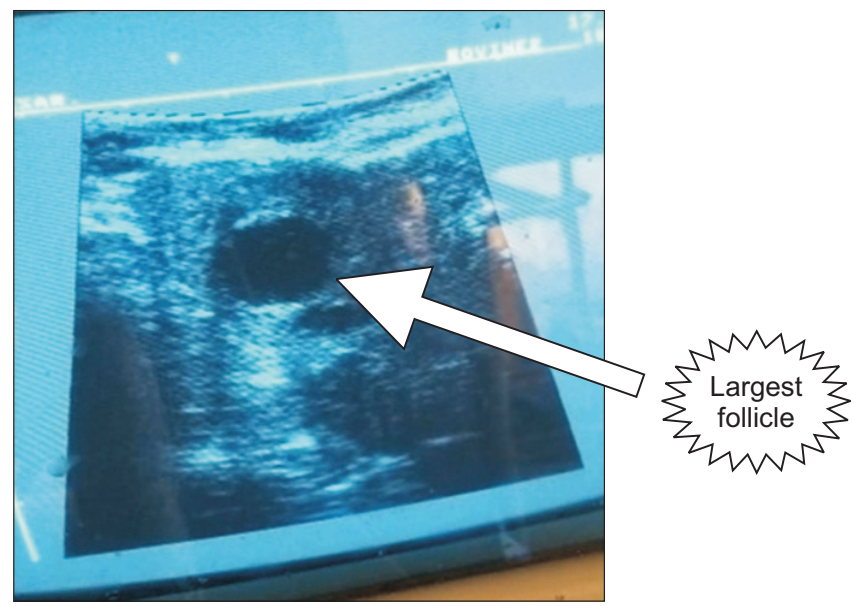

Fig. 1. Image of largest ovarian follicle.
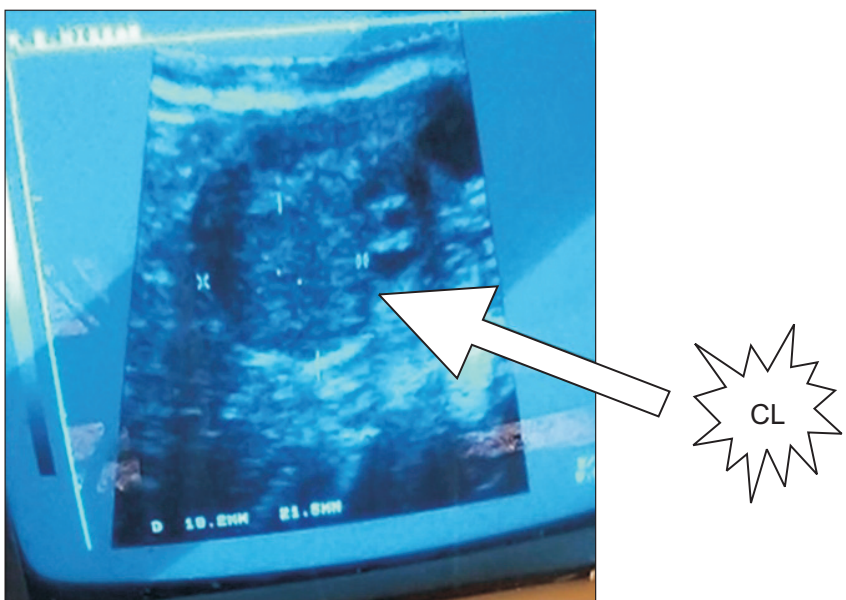

Fig. 2. Image of $\mathrm{CL}$.

\section{Recording of uterine tone and vaginal discharge (UTGD)}

Good uterine tone and good vaginal discharge (GTGD) were recorded in the selected animals at the time of ultrasound examination before performing of artificial insemination (AI). The data were recorded for further analysis.

\section{Pregnancy diagnosis}

Non-return rate and pregnancy diagnosis of the inseminated buffalo cows were performed by ultrasound examination at Day 35 and data were noted for further analysis. Fig. 3 represents the gravid fetus.

\section{Implementation of the injection of PGF $2 \alpha$}

The buffalo cows having mature CL observed by US were injected with PGF2 $\alpha$ (cloprostenol $500 \mu \mathrm{g}$, PragmaBharti Life Science, Pelhar Vasai Fata, Vasai East DistrictThane-401208) intramuscularly and after 72 hours when animals were come heat, again ultrasound examination was done to observe the regressing of $\mathrm{CL}$ and presence of graffian follicle and data were noted. TAI (Timed Artificial Insemination) were performed by the expert veterinarian using frozen semen from CIRB Murrah buffalo bull in presence of graffian follicle with good uterine tone and good vaginal discharge (GTGD) of the buffalo cows. The diameter of the $\mathrm{CL}$ and follicles were recorded for further analysis in the present study. The presence of CL and follicles size after regressing or at the time of AI was measured which presented in Table 1 and 2 .

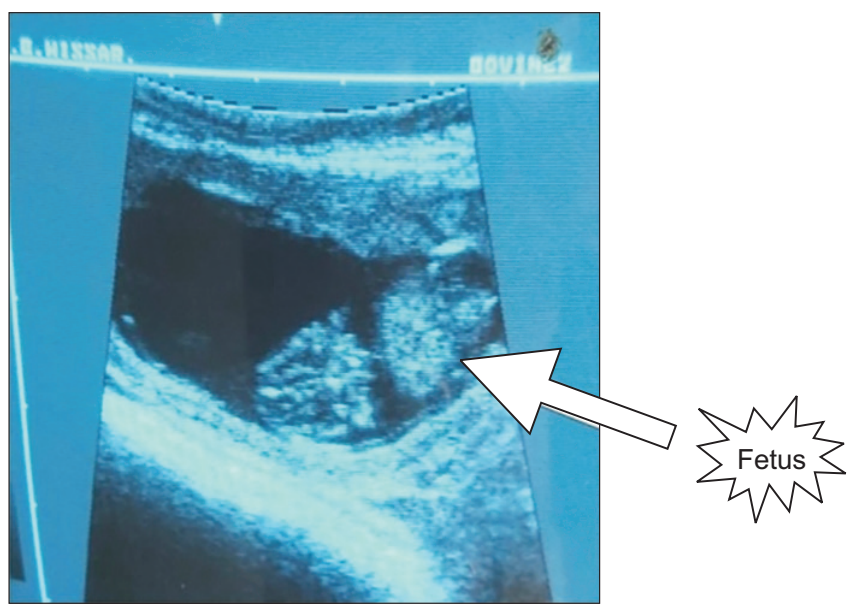

Fig. 3. Image of fetus. 
Rashid et al. Ovarian Dynamics and Pregnancy Rate in Cyclic Buffalo Cows

Table 1. Effect of PG injection on number of follicles in buffalo cows

\begin{tabular}{cccc}
\hline \multirow{2}{*}{$\begin{array}{c}\text { Total number } \\
\text { of animals }\end{array}$} & $\begin{array}{c}\text { Study groups on } \\
\text { the basis of size } \\
\text { of follicles }\end{array}$ & \multicolumn{2}{c}{ Number of follicles } \\
\cline { 3 - 4 } & & At PG injection & $\begin{array}{c}\text { At day 3 post } \\
\text { PG injection }\end{array}$ \\
\hline $\mathrm{n}=28$ & $<3 \mathrm{~mm}$ & $10.89 \pm 0.65^{\mathrm{NS}}$ & $12.43 \pm 0.65$ \\
& $\geq 3-<10 \mathrm{~mm}$ & $1.93 \pm 0.33^{\mathrm{NS}}$ & $1.54 \pm 0.25$ \\
& $\geq 10 \mathrm{~mm}$ & $0.75 \pm 0.09^{\mathrm{NS}}$ & $1.00 \pm 0.10$ \\
\hline
\end{tabular}

Values are Mean \pm SE. NS Non-significant within the row.

Table 2. Effect of PG injection on diameter of follicles and $C L$ in pregnant and non-pregnant buffalo cows

\begin{tabular}{|c|c|c|c|c|c|}
\hline \multirow{2}{*}{$\begin{array}{l}\text { Cyclic } \\
\text { cows }\end{array}$} & \multirow{2}{*}{ Parameter- } & \multicolumn{2}{|c|}{ At PG injection } & \multicolumn{2}{|c|}{$\begin{array}{l}\text { At day } 3 \text { post } \\
\text { PG injection }\end{array}$} \\
\hline & & $\begin{array}{l}\text { Pregnant } \\
\text { cows }\end{array}$ & $\begin{array}{l}\text { Non-preg- } \\
\text { nant cows }\end{array}$ & $\begin{array}{l}\text { Pregnant } \\
\text { cows }\end{array}$ & $\begin{array}{l}\text { Non-preg- } \\
\text { nant cows }\end{array}$ \\
\hline$n=28$ & $\begin{array}{l}\text { Diameter } \\
\text { of largest } \\
\text { follicle } \\
(\mathrm{mm})\end{array}$ & $11.65 \pm 0.41^{\mathrm{NS}}$ & $11.64 \pm 0.54$ & $15.08 \pm 0.36^{* *}$ & $11.87 \pm 0.44$ \\
\hline & $\begin{array}{l}\text { Diameter of } \\
\text { CL (mm) }\end{array}$ & $16.39 \pm 0.42^{\mathrm{NS}}$ & $16.38 \pm 0.29$ & $2.81 \pm 1.29^{*}$ & $9.05 \pm 2.94$ \\
\hline
\end{tabular}

Values are Mean \pm SE. *Significant at $p<0.05,{ }^{*}$ Significant at $p<0.01$ and

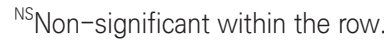

\section{Analysis and interpretation of data}

The chi square test was performed to determine the level of significance in response rate of $C L$ after injecting PG as well as pregnancy rate after AI. The effect of PG at PG injection and at day 3 post PG injection on different follicular diameter groups in pregnant and non-pregnant cows was analyzed by $\mathrm{T}$ test. Average number of different follicular diameter groups, diameter of largest follicle and $\mathrm{CL}$ at PG injection and at day 3 post PG injection were analyzed by "ANOVA" using computerized SPSS 20 software program. The level of significance was considered when $p<0.05$ (significant) and $p<0.01$ (highly significant).

\section{RESULTS AND DISCUSSION}

The effects of PG injection on CL to induce estrus and pregnancy rate in buffalo cows is presented in Table 3 . Result illustrated that after injection of PGF2 $\alpha$, out of 31 buffalo cows $28(90.32 \%)$ were significantly $(p<0.05)$ induced and explore the sign of heat. Result also showed that the pregnancy rate of induced cows were $67.85 \%$
Table 3. Effects of PG injection on $C L$ to induce estrus and pregnancy rate in buffalo cows

\begin{tabular}{|c|c|c|c|}
\hline $\begin{array}{l}\text { Type of } \\
\text { hormone }\end{array}$ & $\begin{array}{l}\text { Efficacy } \\
\text { parameter }\end{array}$ & $\begin{array}{l}\text { Response rate } \\
\text { (\%) }\end{array}$ & $\begin{array}{c}\text { Non-response rate } \\
\text { (\%) }\end{array}$ \\
\hline \multirow[t]{2}{*}{$\begin{array}{l}\text { PGF2 } \alpha \\
\text { (Cloprostenol } \\
500 \mu \mathrm{g})\end{array}$} & $\begin{array}{l}\text { Effects on } C L \text { to } \\
\text { induce estrus } \\
(n=31)\end{array}$ & $90.32^{a}$ & $9.67^{b}$ \\
\hline & $\begin{array}{l}\text { Pregnancy rate } \\
\text { of buffalo cows } \\
\text { with induced } \\
\text { estrus }(n=28)\end{array}$ & $67.85^{\mathrm{a}}$ & $32.14^{a}$ \\
\hline
\end{tabular}

a,b Values differ significantly $(p<0.05)$ within the row.

$(19 / 28)$ through AI, which is significantly $(p<0.05)$ higher than non-pregnancy rate. The PG method of estrous synchronization has proven to be very successful in dairy reproduction i.e. cattle and buffaloes (Odde 1990; Lamb et al., 2000, 2004; Amaya-Montoya et al., 2007). It can be done PGF2 $\alpha$ alone or in combination with GnRH with the use of AI technique for successful in breeding farms for genetic improvement of animals. In buffalo proper heat detection is the main obstacle for application of $\mathrm{AI}$ at accurate time. By the use of ultrasound scanning, easily identify the estrus and luteal condition of animals which helps to perform AI and this techniques is efficient in buffalo to implement this synchronization protocol for increasing productivity. Twagiramungu et al. (1994) observed that when PGF2 $\alpha$ was administered after determining the CL with ultrasonography, 60-70\% animals were detected in estrus within 4 days of post PG injection, which is lower than the present study where $90.32 \%$ animals were detected in estrus within 3 days of post PG administration. Baruselli et al. (2003) and Pursley et al. (1997) reported that the pregnancy rate achieved in cows and buffaloes were $30-50 \%$ through different synchronization and TAI, and this result is inconsistence with the findings of present study where pregnancy rate was $67.85 \%$. Administration of PGF $2 \alpha$ or its synthetic analogues in different regimens to synchronize estrus in normal and sub estrus buffalo cows and results showed that more than $80 \%$ animals showed the estrus $80 \%$ within five days of administration of PGF2 $\alpha$ (Situmorang and Siregar, 1998; Awasthi et al., 1998; Chohan, 1998; Sahasrabudhe and Pandit, 1999; El-Din Zain et al., 2001), which is dissimilar with our present study. This variation might be due to breed of the animal, season (breeding season favor the 
conception rate), nutritional management and hormonal analogue.

The effect of PG injection on number of follicles in buffalo cows is presented in Table 1. Result illustrated that average number of follicles in the groups of $<3 \mathrm{~mm}$ (small), $\geq 3-<10 \mathrm{~mm}$ (medium) and $\geq 10 \mathrm{~mm}$ (large) at PG injection were $10.89 \pm 0.65,1.93 \pm 0.33$ and $0.75 \pm 0.09$, and at day 3 post PG injection were $12.43 \pm 0.65,1.54 \pm 0.25$ and $1.00 \pm 0.10$, respectively. The average number of smaller and larger size of follicles were non-significantly ( $p$ $>0.05$ ) higher at day 3 post PG injection, but the medium size of follicles was non-significantly $(p>0.05)$ higher at PG injection.

Effect of PG injection on diameter of follicles and CL in cyclic buffalo cows is presented in Table 4. Result showed that the diameter of follicles at PG injection and at day 3 post PG injection were $6.83 \pm 0.28 \mathrm{~mm}$ and $7.75 \pm 0.26$ $\mathrm{mm}$, respectively. The diameter of follicles was significantly $(p<0.05)$ higher at day 3 post PG injection. Result also showed that the diameter of CL at PG injection and at day 3 post PG injection were $16.39 \pm 0.29 \mathrm{~mm}$ and $6.75 \pm 1.88 \mathrm{~mm}$, respectively. The diameter of CL was significantly $(p<0.01)$ lower at day 3 post PG injection. In the present study in buffaloes having large CL in one of the two ovaries and large follicle with a single injection of PGF2 $\alpha$ shows good result in starting of estrus after 72 hours administration of PGF $2 \alpha$. Only 3 buffalo cows out of 31 did not respond to injection of single dose of PGF2 $\alpha$. The number of 28 animals was showed very good respond to the treatment of PGF2 $\alpha$ and also they showed good uterine tone and good discharge (GTGD). Estrus synchronization programs improve reproductive efficiency by reducing the length of breeding and calving interval and increasing calf weaning weights. The AI technique can also be used more efficiently in this type of protocol. Result in this study illustrated that the receptive rate of PG on CL is significantly $(p<0.01)$ higher due to PGF2 $\alpha$ regress the CL

Table 4. Effect of PG injection on diameter of follicles and $C L$ in cyclic buffalo cows

\begin{tabular}{cccccc}
\hline \multirow{2}{*}{$\begin{array}{c}\text { Cyclic } \\
\text { cows }\end{array}$} & \multicolumn{2}{c}{ Diameter of follicles $(\mathrm{mm})$} & & \multicolumn{2}{c}{ Diameter of $\mathrm{CL}(\mathrm{mm})$} \\
\cline { 2 - 3 } \cline { 5 - 6 } & $\begin{array}{c}\text { At } \\
\mathrm{n} \text { injection }\end{array}$ & $\begin{array}{c}\text { At day 3 post } \\
\text { PG injection }\end{array}$ & & $\begin{array}{c}\text { At } \\
\text { PG injection }\end{array}$ & $\begin{array}{c}\text { At day 3 post } \\
\text { PG injection }\end{array}$ \\
\hline $\mathrm{n}=28$ & $6.83 \pm 0.28^{*}$ & $7.75 \pm 0.26$ & & $16.39 \pm 0.29^{* *}$ & $6.75 \pm 1.88$ \\
\hline
\end{tabular}

Values are Mean \pm SE. ${ }^{*}$ Significant at $p<0.05$ and ${ }^{*}$ Significant at $p<0.01$ within the row. during the responsive phase and a consequent decrease in the levels of progesterone leading to the development of follicles of the next wave which is responsible for the increasing of estrogen level subsequently estrus (Galina and Orihuela, 2007). The present study also shows that the CL become decreases and growth of follicles increase after applying the prostaglandin injection. Studies carried out by Dhaliwal et al. (1988) and Kamonpatana et al. (1987) revealed that PGF2 $\alpha$ is effective in inducing estrus and this report is more similar with the present studies.

The effect of PG injection on diameter of follicles and $\mathrm{CL}$ in pregnant and non-pregnant buffalo cows is presented in Table 2. Result represented that the diameter of largest follicle at PG injection in pregnant and non-pregnant cows were $11.65 \pm 0.41 \mathrm{~mm}$ and $11.64 \pm 0.54 \mathrm{~mm}$, respectively, which showed that non-significant differences $(p>0.05)$ in between pregnant and non-pregnant cows. Similarly, at day 3 post PG injection the diameter of largest follicle in pregnant and non-pregnant cows were $15.08 \pm 0.36 \mathrm{~mm}$ and $11.87 \pm 0.44 \mathrm{~mm}$, respectively. The diameter of largest follicle at day 3 post PG injection was significantly $(p<0.01)$ higher in pregnant cows compared to non-pregnant cows. In our present investigation, the diameter of CL at PG injection in pregnant and nonpregnant cows were $16.39 \pm 0.42 \mathrm{~mm}$ and $16.38 \pm 0.29$ $\mathrm{mm}$, respectively, which showed that non-significant ( $p>$ 0.05 ) varied in between pregnant and non-pregnant cows. Result showed that the diameter of CL at day 3 post PG injection in pregnant and non-pregnant cows were 2.81 $\pm 1.29 \mathrm{~mm}$ and $9.05 \pm 2.94 \mathrm{~mm}$, respectively. The diameter of CL at day 3 post PG injection was significantly $(p<0.05)$ lower in pregnant cows in comparison to nonpregnant cows. Result illustrated that the diameter of largest follicle was increased and the diameter of CL was decreased in pregnant buffalo cows in response to PG

Table 5. Effect of PG injection on number of follicles in pregnant and non-pregnant buffalo cows

\begin{tabular}{lcccccc}
\hline \multirow{2}{*}{$\begin{array}{c}\text { Study groups } \\
\text { on the basis of } \\
\text { size of follicles }\end{array}$} & \multicolumn{2}{c}{ At PG injection } & & \multicolumn{2}{c}{$\begin{array}{c}\text { At day } 3 \text { post } \\
\text { PG injection }\end{array}$} \\
\cline { 2 - 3 } \cline { 5 - 6 } & $\begin{array}{c}\text { Pregnant } \\
\text { cows }\end{array}$ & $\begin{array}{c}\text { Non-preg- } \\
\text { nant cows }\end{array}$ & & $\begin{array}{c}\text { Pregnant } \\
\text { cows }\end{array}$ & $\begin{array}{c}\text { Non-preg- } \\
\text { nant cows }\end{array}$ \\
\hline$<3 \mathrm{~mm}$ & $11.32 \pm 0.85^{\text {NS }}$ & $10.00 \pm 0.93$ & & $12.84 \pm 0.77^{\text {NS }}$ & $11.55 \pm 1.18$ \\
$\geq 3-10 \mathrm{~mm}$ & $1.89 \pm 0.44^{\text {NS }}$ & $2.00 \pm 0.50$ & & $1.42 \pm 0.32^{\text {NS }}$ & $1.78 \pm 0.40$ \\
$\geq 10 \mathrm{~mm}$ & $0.74 \pm 0.13^{\text {NS }}$ & $0.77 \pm 0.15$ & & $1.11 \pm 0.11^{\text {NS }}$ & $0.77 \pm 0.22$ \\
\hline
\end{tabular}

Values are Mean \pm SE. NS Non-significant within the row. 
injection. According to the previous study (Savio et al., 1988; Ginther et al., 1989) the dominant follicles reach a maximum diameter of approximately $10-20 \mathrm{~mm}$ during estrous cycles in cattle. Yilmaz et al. (2014) reported that follicles at least $12 \mathrm{~mm}$ in diameter were more numerous in follicular phase in water buffaloes. In our present study the average diameter of largest follicle in pregnant animals at the time of estrus day is $15.083 \pm 0.36 \mathrm{~mm}$ which is dissimilar with the findings of Presicce et al. (2005) and they reported that the largest diameter of follicle in first postpartum ovulation as $13.5 \pm 0.8 \mathrm{~mm}$ and $14.1 \pm 0.4$ $\mathrm{mm}$ in primiparous and pluriparous buffaloes, respectively. The variation of largest diameter of follicles with the present study may be due to conduct the experiment in peak breeding season and better management of the animals. Singh et al. (2017) reported that the mean value of CL diameter was significantly lowest on day 5 of the estrus cycle of buffalo cows which indicating immaturity of CL and highest value was recorded on day 14 indicating maturity of CL. In an earlier study, Barkawi et al. (2009) reported that the maximum diameter of $\mathrm{CL}(15 \pm 0.04$ $\mathrm{mm}$ ) on 7th day of cycle in Egyptian buffaloes, which is more or less similar with the present study.

The effect of PG injection on number of follicles in pregnant and non-pregnant buffalo cows is presented in Table 5. Result illustrated that the number of small $(<3 \mathrm{~mm})$, medium $(\geq 3-10 \mathrm{~mm})$ and large $(\geq 10 \mathrm{~mm})$ follicles in pregnant vs non-pregnant buffalo cows at PG injection were $11.32 \pm 0.85$ vs $10.00 \pm 0.93,1.89 \pm 0.44$ vs $2.00 \pm 0.50$ and $0.74 \pm 0.13$ vs $0.77 \pm 0.15$, respectively, which showed that non-significant $(p>0.05)$ difference in between pregnant and non-pregnant buffalo cows. Result also showed that the number of small $(<3 \mathrm{~mm})$, medium $(\geq 3-10 \mathrm{~mm})$ and large $(\geq 10 \mathrm{~mm})$ follicles in pregnant vs non-pregnant buffalo cows at day 3 post PG injection were $12.84 \pm 0.77$ vs $11.55 \pm 1.18,1.42 \pm 0.32$ vs $1.78 \pm$ 0.40 and $1.11 \pm 0.11$ vs $0.77 \pm 0.22$, respectively, which illustrated that non-significant ( $p>0.05$ ) difference in between pregnant and non-pregnant buffalo cows.

\section{CONCLUSION}

Prostaglandin and its analogue have beneficial effects for the induction of estrus or ovulation in buffalo cows after accurate determining of CL with the help of ultrasound scanning, which technique is helpful for the field veterinarians and researchers. Acceptable level of pregnancy rate can be achieved by this protocol and it would be better to minimize the reproductive efficiency of buffalo cows.

\section{CONFLICTS OF INTEREST}

No potential conflict of interest relevant to this article was reported.

\section{ACKNOWLEDGEMENTS}

The authors express their deepest sense of gratitude and thanks to Central Institute for Research on Buffaloes (CIRB), Hisar, India for performing the study on their animals. The authors also express thanks to India Science and Research Fellowship (ISRF), CCST, DST, India and Ministry of Education, Bangladesh for their funding to conduct the research work properly.

\section{AUTHOR CONTRIBUTIONS}

Rashid MH, Phulia SK and Sharma RK designed the study and overall executed the experiments. Rashid $\mathrm{MH}$, Hasan MMI, Juyena NS and Bhuiyan MMU analyses and interpreted the data as well as drafted the manuscript.

\section{AUTHOR'S POSITION AND ORCID NO.}

MH Rashid, PhD Fellow, https://orcid.org/0000-0003-2973-3585

SK Phulia, Principal Scientist, https://orcid.org/0000-0002-0709-4949

MMI Hasan, PhD Fellow, https://orcid.org/0000-0001-5491-8675

MMU Bhuiyan, Professor, https://orcid.org/0000-0002-0870-186X

NS Juyena, Professor, https://orcid.org/0000-0003-0331-0998

RK Sharma, Principal Scientist/Researcher, https://orcid.org/0000-0002-9617-0228

\section{REFERENCES}

Amaya-Montoya C, Matsui M, Kawashima C, Hayashi KG, Matsuda G, Kaneko E, Kida K, Miyamoto A, Miyake Y. 2007. 
Induction of ovulation with GnRH and PGF(2 alpha) at two different stages during the early postpartum period in dairy cows: ovarian response and changes in hormone concentrations. J. Reprod. Dev. 53:867-875.

Awasthi MK, Tiwari RP, Pangaonkar GR. 1998. Induction of estrus and fertility with low dose of prostaglandin F2 alpha in subestrus buffaloes. Indian J. Anim. Sci. 68:1049-1050.

Baruselli PS, Berber RA, Madureira EH, Carvalho NT. 2003. Half dose of prostaglandin F2a is effective to induce luteolysis in the synchronization of ovulation protocol for fixed-time artificial insemination in buffalo (Bubalus bubalis). Braz. J. Vet. Res. Anim. Sci. 40:397-402.

Baruselli PS, Madureira EH, Visintin JA, Barnabé VH, Barnabé RC, Amaral R. 1999. Inseminação artificial em tempo fixo com sincronização da ovulação em bubalinos [Timed artificial insemination with synchronization of ovulation in buffaloes]. Rev. Bras. Reprod. Anim. 23:360-363.

Baruselli PS, Soares JG, Gimenes LU, Monteiro BM, Olazarri MJ, Carvalho NAT. 2013. Control of buffalo follicular dynamics for artificial insemination, superovulation and in vitro embryo production. Buffalo Bull. 32:160-176.

Campanile G, Baruselli PS, Neglia G, Vecchio D, Gasparrini B, Gimenes LU, Zicarelli L, D'Occhio MJ. 2010. Ovarian function in the buffalo and implications for embryo development and assisted reproduction. Anim. Reprod. Sci. 121:111.

Chohan KR. 1998. Estrus synchronization with lower dose of PGF2 alpha and subsequent fertility in subestrous buffalo. Theriogenology 50:1101-1108.

Cooper MJ and Rowson LEA. 1975. Control of the oestrous cycle in Friesian heifers with ICI 80,996. Ann. Biol. Anim. Biochim. Biophys. 15:427-436.

De Rensis F and López-Gatius F. 2007. Protocols for synchronizing estrus and ovulation in buffalo (Bubalus bubalis): a review. Theriogenology 67:209-216.

Dhaliwal GS, Sharma RD, Singh G. 1988. Efficacy of prostaglandin F2-alpha administration for inducing estrus in buffalo. Theriogenology 29:1401-1406.

Drost $\mathrm{M}$ and Elsden RP. 1985. Blastocyst development in the water buffalo (Bubalus bubalis). Theriogenology 23:191.

Edmondson AJ, Fissore RA, Pashen RL, Bondurant RH. 1986. The use of ultrasonography for the study of the bovine reproductive tract. I. Normal and pathological ovarian structures. Anim. Reprod. Sci. 12:157-165.

El-Din Zain A, Abdel-Razek AKh, Anwar MM. 2001. Effect of combined using of GnRH and PGF2 $\alpha$ on oestrus synchronization and pregnancy rate in buffalo-cows. Assiut Vet. Med. J. 45:303-316.

Farin PW, Youngquist RS, Parfet JR, Garverick HA. 1990. Diagnosis of luteal and follicular ovarian cysts in dairy cows by sector scan ultrasonography. Theriogenology 34:633-642.

Galina CS and Orihuela A. 2007. The detection of estrus in cattle raised under tropical conditions: what we know and what we need to know. Horm. Behav. 52:32-38.

Ginther OJ, Knopf L, Kastelic JP. 1989. Ovarian follicular dy- namics in heifers during early pregnancy. Biol. Reprod. 41:247-254.

Kähn W and Leidl W. 1989. Ultrasonic characteristics of pathological conditions of the bovine uterus and ovaries. In: Taverne MAM, Willemse AH (Eds.), Diagnostic Ultrasound and Animal Reproduction. Current Topics in Veterinary Medicine and Animal Science, v. 51., Kluwer Academic Publishers, Dordrecht, pp. 53-65.

Kamonpatana M, Pansin C, Jetna T, Sophon S, Sravasti S, Srisakwattana K. 1987. Factors causing low conception rates when PGF2 is used for oestrus synchronization in swamp buffaloes. Buffalo J. 1:127-143.

Lamb GC, Cartmil JA, Stevenson JS, 2004. Effectiveness of Select Synch (gonadotropin-releasing hormone and prostaglandin F2 $\alpha$ ) for synchronizing estrus in replacement beef heifers. Prof. Anim. Sci. 20:27-33.

Lamb GC, Nix DW, Stevenson JS, Corah LR. 2000. Prolonging the MGA-prostaglandin F2 alpha interval from 17 to 19 days in an estrus synchronization system for heifers. Theriogenology 53:691-698.

Madan ML. 1988. Status of reproduction in female buffalo. Buffalo Production and Health: A Compendium of Latest Research Information Based on Indian Studies. ICAR Publication, New Delhi, India, pp. 89-100.

Odde KG. 1990. A review of synchronization of estrus in postpartum cattle. J. Anim. Sci. 68:817-830.

Plata NI, Spitzer JC, Thompson CE, Henricks DM, Reid MP, Newby TJ. 1990. Synchronization of estrus after treatment with Luprostiol in beef cows and in beef and dairy heifers. Theriogenology 33:943-952.

Prakash BS. 2002. Influence of environment on animal reproduction. National Workshop on Animal Climate Interaction. Izatnagar, India, pp. 33-47.

Presicce GA, Bella A, Terzano GM, De Santis G, Senatore EM. 2005. Postpartum ovarian follicular dynamics in primiparous and pluriparous Mediterranean Italian buffaloes (Bubalus bubalis). Theriogenology 63:1430-1439.

Pursley JR, Wiltbank MC, Stevenson JS, Ottobre JS, Garverick HA, Anderson LL. 1997. Pregnancy rates per artificial insemination for cows and heifers inseminated at a synchronized ovulation or synchronized estrus. J. Dairy Sci. 80:295300 .

Randel RD, Del Vecchio RP, Neuendorff DA, Peterson LA. 1988. Effect of alfaprostol on postpartum reproductive efficiency in Brahman cows and heifers. Theriogenology 29:657-670.

Reeves JJ, Rantanen NW, Hauser M. 1984. Transrectal real-time ultrasound scanning of the cow reproductive tract. Theriogenology 21:485-494.

Sahasrabudhe SA and Pandit RK. 1999. Comparative efficiency of PGF2 alpha administration through different routes in subestrus buffaloes during summer season. Indian Vet. J. 76:128-130.

Savio JD, Keenan L, Boland MP, Roche JF. 1988. Pattern of growth of dominant follicles during the oestrous cycle of heifers. J. Reprod. Fertil. 83:663-671. 
Settergren I. 1987. Female reproduction. State of Knowledge. Proc. International on Milk Buffalo Reproduction. Islamabad, Pakistan, pp. 21-48.

Singh G, Chandolia RK, Dutt R, Saini A, Dalal J, Malik RK. 2017. Comparative study of follicular turn over in cyclic and noncyclic Murrah buffaloes through 2D trans-rectal ultrasonography. Int. J. Curr. Microbiol. App. Sci. 6:3590-3602.

Situmorang P and Siregar AR. 1998. Effects of hormone hCG following injection of Estrumate of reproductive performances of swamp buffalo (Bubalus bubalis). J. Ilmu Ternak Vet. 2:213-217.

Stotts J, Stumpf T, Day M, Wolfe M, Wolfe P, Kittok R, Nielsen M, Deutscher G, Kinder J. 1987. Luteinizing hormone and progesterone concentrations in serum of heifers administered a short half-life prostaglandin (PGF(2alpha)) or long half- life prostaglandin analogue (fenprostalene) on days six or eleven of the estrous cycle. Theriogenology 28:523-529.

Twagiramungu H, Guilbault LA, Proulx JG, Dufour JJ. 1994. Influence of corpus luteum and induced ovulation on ovarian follicular dynamics in postpartum cyclic cows treated with buserelin and cloprostenol. J. Anim. Sci. 72:1796-1805.

Ty LV, Nguyen BX, Son HN, Driancourt MA. 1994. Superovulation and ovarian follicular population of juvenile buffaloes and calves. Anim. Reprod. Sci. 35:191-199.

Yilmaz O, Yazici E, Kahraman A, Ozenc E, Ucar M. 2014. The relationship between ovarian follicle population and follicle size during different stages of estrous cycle in Anatolian Water buffaloes (Bubalus bubalis). Rev. Med. Vet. (Toulouse) 165:111-115. 